\title{
Usefulness of PCR-based assays to assess drug efficacy in Chagas disease chemotherapy: value and limitations
}

\author{
Constança Carvalho Britto
}

Laboratório de Biologia Molecular e Doenças Endêmicas, Instituto Oswaldo Cruz-Fiocruz, Av. Brasil 4365, Pavilhão Leônidas Deane sala 209, 21045-900 Rio de Janeiro, RJ, Brasil

\begin{abstract}
One major goal of research on Chagas disease is the development of effective chemotherapy to eliminate the infection from individuals who have not yet developed cardiac and/or digestive disease manifestations. Cure evaluation is the more complex aspect of its treatment, often leading to diverse and controversial results. The absence of reliable methods or a diagnostic gold standard to assess etiologic treatment efficacy still constitutes a major challenge. In an effort to develop more sensitive tools, polymerase chain reaction (PCR)-based assays were introduced to detect low amounts of Trypanosoma cruzi DNA in blood samples from chagasic patients, thus improving the diagnosis and follow-up evaluation after chemotherapy. In this article, I review the main problems concerning drug efficacy and criteria used for cure estimation in treated chagasic patients, and the work conducted by different groups on developing PCR methodologies to monitor treatment outcome of congenital infections as well as recent and late chronic T. cruzi infections.
\end{abstract}

Key words: Chagas disease - chemotherapy - Trypanosoma cruzi - molecular diagnosis - cure assessment

Chagas disease is an important cause of end-stage cardiomyopathy in Latin America (Rassi et al. 2000), with around 100 million people exposed to the disease (Coura 2007). In the early 1990s, an estimated 16-18 million individuals were reportedly infected with the kinetoplastid protozoan Trypanosoma cruzi, although this figure has recently been revised to around 11 million, revealing an important drop in prevalence (Guzmán-Bracho 2001). Recent surveys indicate that about 200,000 new cases occur yearly in areas where the disease is endemic, representing the third most common parasitic infection worldwide after malaria and schistosomiasis (WHO 2005). The urbanization process in Latin America and immigration trends, however, have led to the disease being diagnosed in non-endemic areas where, even in the absence of the vector, the infection can still be transmitted congenitally, by blood transfusion and by organ transplantation.

In humans, after a short incubation period, an acute phase occurs that, in the absence of specific treatment, persists for about 15-30 days featuring intense parasitaemia, fever and other symptoms. A strong immune response triggers both $\mathrm{B}$ and $\mathrm{T}$ lymphocytes. In this phase, morbidity and clinical symptoms are directly associated with parasitaemia level. Alternatively, the acute infection may also occur as a non-apparent form with few symptoms. After the acute phase of the disease, the

\footnotetext{
Financial support: $\mathrm{CNPq}$ (CCB is fellowship), Papes/Fiocruz Corresponding author: cbritto@ioc.fiocruz.br

Received 13 March 2009

Accepted 1 June 2009
}

patients enter into an asymptomatic chronic stage (subacute or indeterminate phase) with the appearance of T. cruzi-specific antibodies in the blood stream, which lasts throughout life in about two-thirds of the patients. The remaining one-third of chronically infected individuals develop cardiac or digestive complications 10-30 years after the initial infection, at a stage of the disease in which blood and tissue parasites are scarce. About 20$30 \%$ of chronically infected individuals will develop a cardiac clinical form expressed by a large range of manifestations, which can lead to heart failure or sudden death in $70 \%$ and $30 \%$, respectively, of those patients presenting chagasic cardiomyopathy (Manzullo \& Chuit 1999). Approximately $8-10 \%$ of the patients develop digestive manifestations characterized by pathological dilatations of variable severity of the oesophagus and colon.

The pathogenesis of chronic Chagas disease is not completely understood. Parasite persistence with inflammatory reactions (Higuchi et al. 1993, Jones et al. 1993, Brandariz et al. 1995, Bellotti et al. 1996) and other alterations of the host's immune system have been implicated in progressive heart damage caused by infection (Kierszenbaum 1999, Machado et al. 2000). For many years, the traditional parasitological methods, such as haemoculture and xenodiagnosis (XD), could not demonstrate the presence of parasites in damaged tissues. Several studies have implicated autoimmune phenomena as the principal mechanism leading to late cardiac injury (Cunha-Neto et al. 1996, Rassi et al. 2001, Pontes de Carvalho et al. 2002, Iwai et al. 2005, Marin-Neto et al. 2007). This hypothesis is based on the apparent absence of parasites in cardiac inflammatory lesions and the presence of anti-self immune responses in chronic Chagas cardiomyopathy patients, caused by either autoantibodies or autoreactive $\mathrm{T}$ cells, derived by molecular 
mimicry between parasite and host antigens (Kalil \& Cunha-Neto 1996, Girones et al. 2005). This supposition suggested that etiologic treatment would be of little benefit (Cunha-Neto et al. 2006).

Despite the autoimmune response, the role played by the parasite is critical (Jones et al. 1993, Vago et al. 1996) and thus, anti-parasitic therapy may prevent disease progression in chronic Chagas disease (Urbina \& Docampo 2003). The demonstration of T. cruzi components in myocardium by more sensitive methods, such as immunohistochemistry and polymerase chain reaction (PCR), suggested that vestiges of parasites are necessary to trigger the inflammatory process (Higuchi et al. 1993, Jones et al. 1993, Bellotti et al. 1996, Lane et al. 1997, Olivares-Villagómez et al. 1998). Jones et al. (1993) also demonstrated that cardiac tissue adjacent to inflammatory infiltrates yielded PCR-amplified T. cruzi DNA in patients who died of severe chronic chagasic cardiomyopathy. Similarly, Vago et al. (1996) revealed the presence of parasite DNA in oesophageal tissues of patients with chronic digestive Chagas disease. These findings suggest that heart parasitism is the primary stimulus for the perpetuation of myocardial inflammation and is responsible for increased serological response to the parasite (Levin 1996). It is likely that the autoimmune component of Chagas disease is a parasite-induced disorder; therefore, etiologic treatment should focus on clearance of parasites and not on suppressing a presumed pathogenic anti-self response. The few studies that attempted to demonstrate the effectiveness of etiologic treatment were only performed during the last decade of the 20th century, probably based on molecular biology evidence that, at that time, proved that the parasite remained in targeted tissues meaning that they could no longer attribute the etiopathogeny exclusively to immunological mechanisms (Villa et al. 2007). Observational studies found that benznidazole treatment for patients with chronic Chagas disease delayed or prevented clinical progression of heart damage, but was not believed to be able to eliminate the parasite during the chronic phase of infection (Viotti et al. 1994, Fabbro De Suasnábar et al. 2000, Cançado 2002). Conversely, immunosuppressive treatments aggravated inflammatory responses in both experimental models and humans (Andrade et al. 1987, Silva \& Rossi 1990, Bocchi \& Fiorelli 2001).

Although the recent advances in vector control in the Southern Cone countries by an initiative of the Pan American Health Organization (PAHO) and the World Health Organization (WHO) have decreased the incidence of new infections (Schofield \& Dias 1999), two problems are still considerable: the treatment of chronic cases of the disease and the high level of acute cases in some Latin American countries, such as Bolivia and Mexico, where the incidence of infection in some regions reaches levels above $80 \%$ of the population (Medrano et al. 1996). In endemic areas, the transfusional transmission of Chagas disease, due mainly to urbanization and migration processes, represents a great threat (Wendel $\&$ Dias 1992). With this scenario, the major goal of research on Chagas disease is the development of specific chemotherapy that can eliminate the infection from indi- viduals who are acutely or chronically infected, but who have not yet developed cardiac and/or digestive forms of the disease. Research and development of new diagnostic tests and drugs for the etiologic treatment of Chagas disease have been almost non-existent when compared with other non-neglected infectious diseases, such as acquired immunodeficiency syndrome (AIDS). Benznidazole and nifurtimox, the only two drugs available for treatment, have been in the market for more than 30 years and their pharmacokinetic characteristics, formulations, efficacy and secondary effects are far from ideal (Villa et al. 2007). The evaluation of cure of Chagas disease is certainly the more complex aspect of its treatment, leading several times to diverse and controversial results in relation to both parasitological and clinical cures.

\section{Limitations for the use of specific therapy in Chagas disease}

Currently, important questions remain of how best to design therapeutics or prophylactic drugs to treat or prevent Chagas disease as a parasitic infection (Tarleton 2001, Urbina 2001). The specific chemotherapy for human Chagas disease has several limitations, such as the requirement for long-term administration of highly toxic nitroimidazole derivatives that hamper treatment continuity, as well as their limited availability. In addition, natural drug resistance is quite common in the course of human infection, even among parasite populations without previous exposure to these drugs. In this sense, therapeutic results have differed between countries probably due to differences in $T$. cruzi strains from distinct geographical areas. The general assumption, however, is that the earlier the diagnosis is made and the specific treatment initiated, the greater the chance of parasitological cure (WHO 1991, Villa et al. 2007). Nevertheless, one of the greatest concerns in Chagas disease is the absence of reliable methods or a diagnostic gold standard for the evaluation of chemotherapy efficacy in treated patients. Clearance of parasitaemia and disappearance of antibodies (seronegative conversion) are taken together as cure criteria by some authors (Cançado 1963, 1997), whereas others, like Rassi and Luquetti (1992), Andrade et al. (1996) and Sosa Estani et al. (1998), admit a long period of reaction negativation and even low serological titres as criteria of cure. Effectiveness in eradicating the infection depends on the length of time between infection and treatment initiation.

According to the Brazilian Ministry of Health (MS 2005), treatment of T. cruzi infection is recommended during the acute phase, congenital and accidental infections, early chronic phase (children under 15 years old and elderly patients with evidence of recent chronic infection), for patients with AIDS and for those undergoing organ transplantation or receiving immunosuppressive drugs, which present a risk for reactivation of latent infection with T. cruzi (Fragata Filho et al. 1997).

Chemotherapy during the acute stage of infection leads to regression of clinical symptoms and parasitological cure (Cançado 1985), but its effectiveness during the indeterminate and chronic stages remains unclear (Marin-Neto et al. 2007). Studies on the clinical 
evolution of Chagas disease after specific treatment are controversial and results are not convincing due to differences in casuistry, evaluation methods, time of follow-up and data interpretation (Coura \& de Castro 2002). The main limitations in evaluating treatment for chronic Chagas disease arise from the need for longterm follow-up, which usually lasts several decades, and the lack of reliable tests to ensure parasite elimination (Cançado 1985, 1999). It has been proposed that latent forms of T. cruzi parasites present in tissues during the chronic phase of infection are not eliminated by chemotherapy (Brener et al. 2000).

Regardless of intensive research into the development of new drugs that are safer and more efficient for Chagas disease chemotherapy (Urbina 2001), the only drug now available in Latin America is benznidazole [BZ; Rochagan, Rodanil (Roche)], while nifurtimox (Lampit; Bayer) is the drug approved for chemotherapy in the United States. Their administration in the acute and recently acquired chronic phases of infection demonstrated significant trypanocidal activity (Rassi \& Luquetti 1992, Andrade et al. 1996, 2004). Benznidazole ( $N$-benzil-2-nitro-1-imidazole-acetamide) has direct action against both the circulating (trypomastigote) and tissular (amastygote) forms of $T$. cruzi. Its efficacy varies according to the phase of the disease, dose and duration of treatment, age, period of follow-up after therapy and the tests used to assess parasite clearance.

Nifurtimox and benznidazole have significant activities in the acute phase, with up to $80 \%$ of parasitological cure rates in treated patients (Andrade et al. 1992). However, their efficacies vary according to the geographical area, probably due to differences in drug susceptibility among different $T$. cruzi strains, a fact correlated with the biological characteristics of the parasite (Andrade et al. 1992, Cançado 1999). In the past decade, benznidazole has been reported to have significant curative activity in recent chronic disease (up to a few years post-infection), with up to $60 \%$ parasitological cure rates observed in infected children of Argentina and Brazil treated with this compound (Sosa-Estani \& Segura 1999, Andrade et al. 2004). Similar results were obtained in Chile with nifurtimox (Solari et al. 2001). After the introduction of nifurtimox and benznidazole, few compounds were assayed in chagasic patients. The results obtained with allopurinol (ALLO) [4-hydroxypyrazolo $(3,4-d)$ pyrimidine HPP] in experimental animals and the knowledge about its mode of action led to clinical assays for the treatment of Chagas disease (Lauria-Pires et al. 1988, Galleano et al. 1990).

The role of anti-parasitic treatment in the late chronic phase of Chagas disease remains unclear. A limited efficacy of available drugs has been observed in this phase of the disease, in which parasitological cure is achieved in $0-20 \%$ of treated patients (OPAS/OMS 1998, LauriaPires et al. 2000, Britto et al. 2001, Guedes et al. 2006). On the other hand, some studies performed with benznidazole have been remarkably consistent in showing moderate to significant efficacy in long-term chronic infections (de Castro et al. 2006, Sosa-Estani \& Segura 2006, Viotti et al. 2006). For instance, Viotti et al. (2006) reported the success of drug treatment in arresting disease progression in subjects who have been infected for more than 20 years.

The capacity of any given drug to eradicate the infection is dependent on intrinsic host features, such as immune status, the susceptibility of a particular T. cruzi genotype to the drug, as well as the drug pharmacokinetic properties and toxicity in the host and the duration of treatment. Other chemotherapeutic agents, such as ALLO and itraconazole (ITRA), are being evaluated for the treatment of chronic Chagas disease, but their advantages over benznidazole have not been determined.

\section{Heterogeneity of $T$. cruzi populations}

T. cruzi is composed of a heterogeneous population of clones with broad biological and genetic variability circulating in domestic and sylvatic cycles, which includes humans, insect vectors and animals. Moreover, this parasite undergoes long-term clonal evolution that predicts correlation among phylogenetic divergence. The parasite's biological properties play an important role in the disease pathogenesis (morbidity) and may affect drug efficacy (Andrade et al. 1975, Tibayrenc et al. 1986, Andrade \& Magalhães 1996, Revollo et al. 1998, Toledo et al. 2003, 2004). The occurrence of naturally resistant T. cruzi strains demonstrated in experimental models (Filardi \& Brener 1987, Murta et al. 2008) is supposed to be one of the most important factors explaining the low rates of cure in some treated chagasic patients from endemic zones, as seen in Central Brazil in patients infected with strains of the biodeme type III, Z1 (T. cruzi I) as compared with those infected with biodeme II, Z2 (T. cruzi II) (Andrade et al. 1992). In fact, the occurrence of predominant strains exhibiting different susceptibility levels (in specific geographic areas) has been associated with a high variability of clinical symptoms concerning treated patients. Studies have demonstrated that the socalled type III biodeme, of which the prototype is the Colombian strain, is highly resistant (Andrade et al. 1985, Andrade \& Magalhães 1996, Toledo et al. 2003, 2004).

In experimental mixed infections with parasites from different $T$. cruzi genotypes, interactions between subpopulations may occur, resulting in important changes in the parasites' biological characteristics and the evolution of infection (Deane et al. 1984, da Silveira Pinto et al. 1998, 2000, Martins et al. 2006, 2007). Mixed infections show responses to benznidazole treatment distinct from the expected response based on single-infection analyses (Martins et al. 2007), suggesting that the expected correlation between susceptibility to treatment is difficult to establish for dual infections when genetic combination occurs.

The existence of a high incidence of mixed infections in humans (Solari et al. 2001) and vectors (Bosseno et al. 2000) has been verified and raises questions about its important consequences regarding morbidity, the dynamics of parasite transmission and the response to chemotherapy. The contradictory results obtained in human treatment by different authors are probably influenced by the occurrence of mixed infections, since individuals in areas where the disease is endemic may be re-infected 
several times (Brenière et al. 1998). These results emphasize the importance of phylogenetic diversity of $T$. cruzi genotypes in approaches towards diagnosis and treatment of Chagas disease.

\section{Usefulness of PCR for establishing drug efficacy}

Most human infections with $T$. cruzi are only detected in the chronic phase, characterized by subpatent parasitaemia and scarce tissue parasitism. Demonstration of treatment efficacy is hampered by the lack of reliable criteria of cure, as well as the rather poor sensitivity of conventional parasitological practices. Microscopic methods lack sensitivity, and XD and haemoculture may require 30 days or more, and also lead to false-negative results. Both methods have a tendency to increase their positivity with the number of tests performed, amount of blood employed, cultivation medium, interval of time between blood collection and cultivation and other factors emphasized by Chiari et al. (1989). Moreover, these tests are time-consuming and laborious, requiring special laboratory biosecurity conditions (Brener 1962, Gomes et al. 1999). In addition, post-therapeutic monitoring in the chronic phase of Chagas disease still constitutes a major challenge due to the long-term persistence of specific antibodies that are detected by conventional serology for several years, despite repeated negative direct parasite detection tests (Andrade et al. 1988, 1991); nonconventional serology is not frequently used (Krettli \& Brener 1982). The presence of lytic antibodies has therefore been proposed as an indicator of active ongoing infection and treatment failure (Krettli et al. 1982, Galvão et al. 1993). This test requires the use of live, infectious trypomastigotes and is not practical for routine use in the evaluation of chemotherapeutic agents or in clinical management of chagasic patients (Krettli et al. 1984).

In an effort to develop more sensitive assays, PCR technology has been introduced to specifically detect T. cruzi DNA in blood samples from chagasic patients, opening new possibilities in the diagnosis and follow-up assessment of chemotherapy (Moser et al. 1989, Sturm et al. 1989, Avila et al. 1991, 1993, Britto et al. 1993, 1995, 2001, Wincker et al. 1994a, b, Junqueira et al. 1996, Gomes et al. 1998, 1999, Castro et al. 2002, Galvão et al. 2003). Reconstitution experiments showed that PCR procedures are able to detect the equivalent of a single parasite cell in 10-20 mL of whole blood (Moser et al. 1989, Avila et al. 1991, Britto et al. 1993). However, there are large genetic differences between distinct $T$. cruzi strains related to their biological variability, such as virulence or variable susceptibility to the immune response (control of parasitaemia) developed after the acute phase of human infection. Consequently, genetic strain differences may influence parasitaemia in man and partially explain the discrepancies of PCR sensitivity between studies carried out in different endemic areas. For instance, in Bolivia and most part of Brazil, in areas where T. cruzi II stocks circulate, PCR shows high sensitivity, contrasting with areas from the Brazilian Amazon and Mexico, where only T. cruzi I stocks occur (Avila et al. 1993, Wincker et al. 1994a, b, 1997, Zingales et al. 1998, Fernandes et al. 2001, Coura et al. 2002).
Several therapeutic studies confirm the usefulness of usual PCR strategies to evaluate treatment outcome in either acute or chronic cases of Chagas disease (Russomando et al. 1998, Lauria-Pires et al. 2000, Britto et al. 2001, Solari et al. 2001, Galvão et al. 2003, Schijman et al. 2003, Zulantay et al. 2004, Sánchez et al. 2005). PCR is a helpful tool for the early detection of treatment failure when comparing drug efficacy, tolerance, therapeutic schemes, periods of follow-up and cure criteria. Considering that the suppressive activity on parasitaemia is almost immediate after treatment initiation in the case of T. cruzi populations susceptible to the drug, the assessment of treatment outcome is mainly parasitological; anti-T. cruzi IgGs remain positive practically lifelong. The higher PCR sensitivity for T. cruzi detection confirms its potential use for evaluating chemotherapeutic efficacy compared with traditional parasitological methods, such as XD and haemoculture.

Other distinct factors may contribute to the overall performance of PCR assays: the epidemiological characteristics of the study populations, the blood volume collected, the method used to isolate DNA, parasite targetsequences [e.g., nuclear satellite DNA or kinetoplast DNA $(\mathrm{kDNA})]$ and primers selected for PCR, reagents used and thermo-cycling conditions. The blood sample volume is an important factor to be considered in chronic patients with low levels of parasitaemia following treatment, and the differences in PCR sensitivity can be explained by the intermittent presence and quantity of circulating parasites at the time of blood collection (Castro et al. 2002).

Whether a positive PCR reflects detection of intact parasites or circulating DNA derived from lysed organisms is not clear. Tarleton and Zhang (1999) reported that after intramuscular injection of a large quantity of $T$. cruzi kDNA in mice, PCR performed on blood samples was positive up to $48 \mathrm{~h}$ after inoculation, suggesting that parasite DNA detected by PCR derives from intact, extracellular or recently lysed parasites.

If so, PCR is a rapid and safe indicator of the parasite's susceptibility to drugs, allowing early therapy modification in cases of resistance or reactivation of chagasic infection (Schijman et al. 2000, Lages-Silva et al. 2002). According to Galvão et al. (2003), there is no guarantee that a single "flash" of a negative PCR means parasitological cure, especially when the wellknown waves of parasitaemia during the long course of Chagas disease are taken into account. A negative posttreatment PCR result may be indicative of the absence of parasite DNA at that moment. Negative results for both, serology and PCR are probably indicative of cure. The value of parasitological tests lies mainly in the positive results they yield; thus, a positive PCR in blood may reflect treatment failure. Hence, PCR can be used as an early marker of specific chemotherapy resistance years before serological reversion [long-lasting sustainability of negative seroconversion, as pointed out by Rassi and Luquetti (2003)]. If the persistence of positive PCR results is considered a therapeutic failure, assessment of parasite load by quantitative real-time PCR could still be correlated with the impact of trypanocidal treatment on the disease evolution. 
Treatment of congenital infections - T. cruzi congenital transmission may occur in some or all pregnancies in the infected mother, whether in the acute or chronic stages, normally with oligoparasitaemia and usually as an asymptomatic disease (Bittencourt 1992). Variable rates of congenital transmission have been reported in different geographical areas where distinct parasite strains predominate, suggesting that parasite genotypes might play a role in the risk of congenital transmission. Moreover, in cases of transmission, it is unknown if the whole maternal T. cruzi population or certain clones are preferentially transmitted by the transplacental route (Burgos et al. 2007). The prevalence of T. cruzi infection among pregnant women ranges from 2-51\% in urban areas and from $23-81 \%$ in rural regions of Latin America (Freilij \& Altcheh 1995).

Standard serodiagnosis of T. cruzi infection in infants born to seroreactive women has low positive predictive value, since the presence of anti- $T$. cruzi IgG antibodies in the newborn may be due to passive transfer of maternal IgG antibodies, which in the non-infected infant would normally disappear around the sixth month of age (Moya et al. 1989, Freilij \& Altcheh 1995, Luquetti 1997). Moreover, a small proportion of infected newborns is seronegative. The detection of $\operatorname{IgM}$ antibodies against $T$. cruzi is not satisfactory (Freilij \& Altcheh 1995, Blanco et al. 2000). Therefore, the diagnosis of congenital infections usually relies on microscopic observation of bloodstream trypomastigotes, which is more effective by microhaematocrit concentration technique in infants less than six months of age (Freilij et al. 1983, Freilij \& Altcheh 1995). Anti-parasitic treatment has greater success in newborns close to birth and is strongly indicated (Freilij \& Altcheh 1995, Luquetti 1997). In search of more sensitive laboratory tests to detect infection and evaluate treatment outcome in congenital infections, PCR appears to be a promising laboratory tool (Russomando et al. 1998, Schijman et al. 2003, Virreira et al. 2005, Duffy et al. 2009).

Russomando et al. (1998) examined 58 infants born to seropositive mothers for congenital transmission of Chagas disease in Paraguay using direct microscopy, immunofluorescence for anti-T. cruzi IgM antibodies and PCR targeted to nuclear genomic markers (Moser et al. 1989). It was possible to detect $T$. cruzi DNA from $100 \mathrm{uL}$ of plasma in six newborns $(10 \%)$ on the day of birth who were IgM negative. Treatment with benznidazole ( $7 \mathrm{mg} / \mathrm{kg}$ of body weight) was given in two daily doses for 60 days and was initiated on the day T. cruzi infection was confirmed by direct microscopic observation or haemoculture and positive PCR. The infected infants were followed-up for four years by serology and PCR. Serology remained positive 3-8 months posttreatment and the evaluation of treatment effectiveness by PCR presented higher sensitivity, as soon as 15 days after treatment. These data suggested that the later the treatment is initiated, the later the negative seroconversion takes place. The authors concluded that conventional parasitological and serological techniques were not efficient enough to provide early diagnosis of con- genital Chagas disease, especially in rural areas where the disease is endemic. PCR sensitivity was usually higher than haemoculture and practically confirmed $100 \%$ treatment efficacy in association with conventional serology negativation.

Schijman et al. (2003) performed the first prospective PCR study in a cohort of paediatric patients with congenital Chagas disease from a non-endemic area in Argentina, without risk of vectorial re-infections. The study focused on the evaluation of anti-parasitic therapy in patients with congenital infection, diagnosed and monitored by conventional and PCR-based assays targeting the parasite mitochondrial genome or kDNA. A competitive PCR was carried out in order to characterize the bloodstream parasite load in patients at the time of diagnosis, as well as during post-treatment followup. To evaluate the outcome of 40 patients undergoing anti-parasitic treatment after 2-3 years post-chemotherapy, the children were classified into three age groups: GI ( $<3$ months of age), GII ( 7 months- 2 years old) and GIII ( $>3$ years old). Patients from both GII and GIII represented the undetermined phase of Chagas disease. Cure was demonstrated by both negativation of PCR and serology in $100 \%$ of infants from GI, in $66.7 \%$ of children from GII and in only $12.5 \%$ of GIII cases. In those infants who started therapy in their first months of life ( $<3$ months), cure was achieved early after treatment, in accordance with previous studies (Blanco et al. 1999, 2000). In these cases, PCR became negative earlier or at the same stage as serology did. The authors did not observe differences between nifurtimox or benznidazole for toxicity, clinical manifestations, serological and PCR outcome. They concluded that PCR is a helpful tool for early detection of treatment failure in patients who initiate therapy at the undetermined phase of the disease. The dissociation between post-treatment persistent negative PCR results with positive conventional serology after three years of follow-up observed in 20 out of 30 undetermined Chagas disease patients (GII + GIII) was in agreement with previous findings in treated chronic patients presenting reactivity by conventional serology with clearance of lytic antibodies (Galvão et al. 1993). The investigation by Schijman et al. (2003) reinforces the need to screen all pregnant women living in or emigrating from endemic areas in order to provide their newborns with an early accurate diagnosis for a more successful treatment outcome.

Treatment in early life - It is well documented that infants infected during the early years of life represent those patients amenable to specific treatment with the greatest possibility of cure (Rassi \& Luquetti 1992, Villa et al. 2007). Children better tolerate a long-term treatment and present high indices of cure, as demonstrated by two randomized placebo-controlled trials with benznidazole in Brazil (Andrade et al. 1996) and in Argentina (Sosa Estani et al. 1998), where negative seroconversion was estimated in around $60 \%$ of the benznidazole-treated children. Thus, in acute and recent infection cases, an effective treatment might prevent the progression of infection to disease and its complications. 
Solari et al. (2001) evaluated 66 Chilean chagasic children from 0-10 years old treated with nifurtimox and further monitored every three months in the first year and every six months during the second and third year post-therapy. Chemotherapy efficacy was assessed by using PCR for T. cruzi kDNA, XD and serology (ELISAIgG and indirect haemagglutination). The results showed that serology still remained positive and serum titres unchanged at 36 months following treatment, except in the two youngest cases ( 1 and 14 months old) out of seven cases ranging from 1-20 months old. Therapeutic effectiveness, as determined by serological cure, seemed to depend on the delay between infection and the start of treatment. Before therapy, all children were positive by PCR. The rate of parasitological cure in 0-10 yearold children was variable and dependent on the region in which those children lived. Several months were required to obtain a prolonged negative result by PCR, even though positive XD rapidly dropped 3-6 months after treatment from $79.1-1.6 \%$, probably due to the lower sensitivity of the method. In this study, the slow rate of PCR conversion could be explained by the late administration of the drug after infection as compared to the early efficacy of treatment in congenital cases, from a few days to three months (Russomando et al. 1998). According to Solari et al. (2001), PCR was the most effective test to monitor children three years post-chemotherapy, when all treated children converted from positive to negative, and no significance was found between patient age and PCR conversion. Conventional serology, however, remained positive three years post-chemotherapy in most cases.

The investigation conducted by Galvão et al. (2003) used a PCR based on kDNA to assess the rate of chemotherapy failure. They studied a well-characterized Brazilian cohort of T. cruzi seropositive schoolchildren previously enrolled in a field trial of benznidazole efficacy who lived in a highly endemic rural area in Central Brazil. Paired blood samples $(5 \mathrm{~mL})$ from 111 children were taken at baseline and 36 months after treatment with either benznidazole $(n=58)$ or placebo $(n=53)$. At the end of follow-up, PCR was positive in $39.6 \%$ of the treated group versus $64.2 \%$ of the placebo group, indicating that untreated patients had a 1.6-fold higher chance of remaining PCR-positive than those who received specific chemotherapy $(p=0.01)$. In the study, the possibility of re-infection was discarded. Among those who received benznidazole, $22.6 \%$ did not present a decrease in the indirect immunofluorescence (IIF) titres and PCR continued to be positive for $39.6 \%(p>0.05)$, pointing out the proportion of benznidazole failure after a 3-year follow-up. An adequate correlation could be found between a high proportion of negative PCR results and a decrease in antibody titres in the treated group. PCR positivity occurred in patients without reductions in antibody titres. In the placebo group, a higher proportion of PCR positivity (64.2\%) was detected in agreement with the absence of a decrease in IIF titres (77.4\%). In this work, PCR was confirmed as a useful tool for revealing therapeutic failure of $T$. cruzi infection on a short-term basis, although the authors highlight the possibility that among treated children with negative PCR, some of them were expected to shift to positive PCR during long-term follow-up, especially when the wellknown waves of parasitaemia during the long course of Chagas disease are taken into account.

Treatment of chronic infections - Effective chemotherapy of $T$. cruzi infection is needed due to the enormous burden of chronic infections imposed on human populations living in endemic areas in which active insect-vector transmission occurs. While the elimination of Chagas disease has been considered a reasonable public health goal, controversies still remain about the efficiency of trypanocidal chemotherapy, especially in chronic asymptomatic individuals. It is recommended that late chronic infections without clinical manifestation or with mild cardiac or digestive symptoms should be treated during 60-90 days, in accordance with the tolerance to the drugs, aiming to prevent or reduce the evolution of Chagas disease to more severe forms (Luquetti 1997, Coura \& de Castro 2002). In spite of the evidence that nitroimidazole derivatives improve parasite-related outcomes in both children and adults with chronic asymptomatic T. cruzi infections, it has not yet been definitely proven whether the reduction in parasite load translates into improved clinical outcomes (MarinNeto et al. 2008). Up to $80 \%$ of patients treated during the late chronic infection do not achieve parasitological cure as assessed by the persistence of positive serology, now confirmed using PCR-based methods.

The great advances in vector control in the South Cone countries and demonstration of the parasite in chronic patients by more sensitive diagnostic tests indicated the urgency to discuss the etiologic treatment during this phase, and thus reinforcing the need to find drugs with more efficacy and less toxicity. Agents such as ALLO and ITRA have been evaluated for treatment of chronic infections, but their advantages over benznidazole have not yet been determined. One of these studies showed that ITRA, used as an anti-fungal drug for 20 years, produced parasitological cure in 53\% of chronic chagasic patients $(6 \mathrm{mg} / \mathrm{kg} / \mathrm{day}$ for 120 days), whereas ALLO $(8.5 \mathrm{mg} / \mathrm{kg} /$ day for 60 days) was able to eliminate T. cruzi infection in $44 \%$ of the treated patients (Apt et al. 1998). The criteria for parasitological cure were the maintenance of negative XD and/or complement-mediated lysis for at least four years of follow-up. Double-blind randomized longitudinal studies must still be performed to re-evaluate the efficacy of these drugs for treatment of Chagas disease.

Cure assessment in chronic infections is controversial and difficult to demonstrate, mainly due to the lack of sensitive or specific tests to document parasitological cure (Krettli et al. 1984, Galvão et al. 1993). However, in the 1990s, assays based on PCR were used to detect T. cruzi DNA in the blood of chronic chagasic patients with an adequate sensitivity (a single parasite cell in 10$20 \mathrm{~mL}$ of whole blood) and proven to be a promising tool for evaluating parasitological failure after specific etiologic treatment in chronic infections (Avila et al. 1991, Britto et al. 1993, 1995, 2001, Wincker et al. 1994a, b, Junqueira et al. 1996, Gomes et al. 1999). 
Britto et al. (1995) proposed for the first time the use of PCR tests to monitor chagasic patients submitted to specific treatment as a complement to serological investigation of cure. They assessed the performance of a PCR assay directed to T. cruzi kDNA for the evaluation of chemotherapy outcome in 32 benznidazole-treated seropositive chronic patients attending the Hospital of Infectious Diseases from Fiocruz, in Rio de Janeiro. Positive amplification results were observed in only nine out of 32 treated patients who remained reactive with conventional serology, even after a mean period of five years post-treatment. XD was not able to detect parasite persistence in five out of the nine PCR-positive treated patients. Consequently, PCR appears remarkably useful for early detection of cases refractory to therapy and should be employed in association with serology for the assessment of cure in chronic Chagas disease infection.

Lauria-Pires et al. (2000) performed a 10-year follow-up study to determine the effectiveness of nitroderivative therapy in a cohort consisting of 45 treated chronic patients with severe electrocardiographic alterations $(62 \%$ treated with nifurtimox and $38 \%$ with benznidazole), 46 chronic chagasic individuals who did not receive therapy and 41 uninfected controls. Anti-T. cruzi antibodies were consistently lower one year after treatment than 10 years thereafter $(p<0.001)$. Blood from all treated and $93.7 \%$ of untreated chagasic patients yielded PCR-amplified product from the parasite nuclear DNA, indicating active infection. A competitive PCR demonstrated no significant difference in parasite load between treated $(13.8 \pm 14.9$ T. cruzi/mL of blood) and untreated (20.1 \pm 22.6$)$ patients. The evidence of ongoing infections was in accordance with the immunological results, which were indistinguishable in the treated and untreated groups of patients. In this study, treatment with nitrofuran and nitroimidazole compounds did not lead to parasitological cure and did not alter the progression of heart disease in chronic chagasic patients. Progressive electrocardiographic alterations were recorded in treated as well as untreated patients, the proportions not being statistically different. The authors suggest that nitroderivative therapy may discharge parasitaemia as a consequence of drug-induced immunosupression and parasite resistance, probably through the selection of highly virulent parasite clones.

In the study by Britto et al. (2001), PCR and XD performed 20 years after trypanocidal chemotherapy were compared aiming to investigate parasite clearance in 85 chronic asymptomatic individuals who were previously diagnosed as unquestionably chagasic by XD. These individuals inhabited two distinct geographic areas from Brazil in which vector transmission was interrupted for more than 20 years, and were submitted to specific treatment with either benznidazole or nifurtimox (37 in the acute phase and 48 in the chronic phase). The untreated group consisted of 15 xenopositive chronic asymptomatic individuals that received placebo. Treatment in the acute phase yielded PCR-negative results in $73 \%$ of the cases (endpoint analysis), while XD negativation was observed in $86 \%$. Regarding the individuals treated during the chronic phase, PCR was negative in $65 \%$ and $83 \%$ had XD-negative results 20 years after treatment. For the untreated group, XD was not able to find the parasite in $73 \%$, in which $36 \%$ were positive by the molecular approach. It is important to highlight that a negative PCR result might be indicative of the absence of parasite DNA at that moment. Herein, as only one point in time was analyzed, a negative result could not be assumed as definitive cure. The agreement of negative results between serology and PCR is probably indicative of cure. In this investigation, only 10 individuals that were considered seronegative several years after the start of chemotherapy unequivocally presented negative results by PCR, demonstrating the elimination of circulating parasites in these cases. Seventeen individuals had their antibody titres decreased to such a level, and the final results were considered doubtful; 16 of them presented negative PCR. The results supported the advantage of PCR over conventional parasitological techniques to demonstrate persistent infections in chronic chagasic patients undergoing chemotherapy.

Zulantay et al. (2004) investigated the use of PCR and hybridization assays to detect T. cruzi in 52 chronic chagasic patients from a highly endemic region of Chile six years following therapy with either ITRA or ALLO. All patients yielded negative XD six years post-treatment with either drug; XD was performed at the same time as blood sample collection for PCR. The PCR alone enabled the identification of T. cruzi kDNA in $40 \%$ of patients treated with ITRA and in $60 \%$ of those ALLOtreated. When associated with an isotopic hybridization step (kDNA as probe), PCR positivity was higher in the group treated with ITRA $(60 \%)$ and a slight reduction of PCR sensitivity was observed in patients that received ALLO, due to only one case where the hybridization result was not concordant and, consequently, the fraction of PCR positivity dropped to $53 \%$. The authors reinforced the use of PCR coupled to hybridization to demonstrate parasite persistence in chemotherapeutic evaluation.

In the work by Sánchez et al. (2005), a combination of PCR and flow cytometry analysis of anti-live trypomastigote antibodies (FC-ALTA) was performed to monitor parasite clearance in 54 chronic patients treated with ALLO $(n=31)$ or ITRA $(n=23) 10$ years earlier. All patients maintained positive conventional serology up to 10 years follow-up. XD gave positive results in $35.5 \%$ and $60.9 \%$ of the ALLO and ITRA-treated groups, respectively, while both PCR and FC-ALTA were positive in $74.2 \%$ ALLO and $87.0 \%$ ITRA. Discordant results between PCR and FC-ALTA were as follows: (i) 13\% of total patients were negative by PCR and positive by FC-ALTA and (ii) 5\% gave positive PCR results with negative FC-ALTA. Only one case where both tests were negative was considered cured. The results did not show differences in efficacy between the drugs and reinforced the relevance of using sensitive tools such as PCR and FC-ALTA to follow-up patients with chronic Chagas disease.

Coronado et al. (2006) studied the distribution of $T$. cruzi clones after treatment failure with ITRA or ALLO 
12 years after therapy completion in chronically infected individuals in an endemic area free of vectorial transmission in Chile. Blood samples from treated and untreated individuals were used to detect the parasite by PCR following confirmation with hybridization using total kDNA as the universal probe; FC-ALTA was also employed to detect active infection. In parallel, XD was performed with Triatoma infestans fed from the same group of patients. Southern-blot analysis of PCR products using two samples from each patient (blood and $\mathrm{XD})$ was performed with a panel of four genotype-specific probes corresponding to T. cruzi clones 19 (TcI), 32 (TcIIb), 39 (TcIId) and 43 (TcIIe). The results revealed complex hybridization patterns for both blood and insect samples, indicative of infection with more than one clone in some patients. No evidence of cure was assessed by FC-ALTA or PCR with either blood or XD samples. The percentages of PCR-positive samples in blood $(89.5 \%)$ and XD samples (91.2\%) increased to $100 \%$ and $96.5 \%$, respectively, after hybridization. Although the quantification of parasitaemia levels was not performed, the authors predicted that the lower or higher percentage of a particular T. cruzi clone may be indicative of parasite susceptibility or resistance to chemotherapy. Clone TcI was present in $69.2 \%$ of the XD samples from the ALLO-treated group compared to the control group (non-treated, 29.6\%; $\mathrm{p}=0.0178$ ), suggesting resistance of this clone to ALLO. When the ITRA-treated group was compared with the control group, significant differences were found in both blood and XD samples. In blood, the clone TcIIb was detected in $35.5 \%$ of treated individuals and in $66.7 \%$ of the control group $(\mathrm{p}=0.0207)$, which suggested susceptibility of this clone to ITRA. Regarding the XD samples, clone TcI was observed in $82.3 \%$ of the ITRA-treated individuals but only in $29.6 \%$ of the control group $(p=0.0006)$, thus also indicating resistance of this clone to ITRA. No significant differences were found for the T. cruzi clones TcIId and TcIIe in the treated (ALLO and ITRA) and non-treated groups.

The results from Coronado et al. (2006) obtained for the first time in humans were able to confirm previous data using murine models concerning the association between T. cruzi phylogenetic diversity and chemotherapeutic response (Andrade et al. 1985, Toledo et al. 2003). In general, these studies suggest that susceptibility or resistance to a drug depends on the $T$. cruzi genotype, thus indicating that the appropriate drug or combination of drugs should depend upon the infective parasite clone or mixture of clones present in a particular host. In situations relating to parasitological cure failure, the best adapted T. cruzi clone to a host would be associated with the resistance to chemotherapy ( $\mathrm{TcI}$ increased in patients treated with ALLO and ITRA). In contrast, the lower adaptation of $T$. cruzi clones to a host would be correlated with drug susceptibility (TcIIb decreased only in the ITRA-treated patients).

The efficacy of benznidazole therapy in preventing clinical complications in patients with pre-existing cardiac disease is now being evaluated in the scope of the BENznidazole Evaluation for Interrupting Trypano- somiasis (BENEFIT) study, conducted by the Canadian Institutes of Health Research and WHO/TDR in collaboration with investigators in Latin America and expected to be completed in 2011 (5 years follow-up). BENEFIT is a multicentre, randomized, double-blind, placebocontrolled trial of 3,000 patients with Chagas cardiomyopathy in Latin America, thus representing the largest trial yet conducted on Chagas disease (Marin-Neto et al. 2008). The study was designed to clarify the role of trypanocidal therapy for prevention of cardiac disease progression and death and also comprises a sub-study to evaluate the effects of benznidazole on parasite clearance using PCR-based methods (qualitative and quantitative assays). The BENEFIT program will provide a unique opportunity for better understanding of the clinical progression of chronic Chagas cardiomyopathy and it is expected to provide conclusive information on the role of etiologic treatment in this phase of the disease (Marin-Neto et al. 2008).

\section{Final comments}

Great efforts are being made in countries of South America to control Chagas disease transmission by either insect vectors or blood transfusion, although more effective chemotherapy is needed for the million people who are already infected. There is a need for new drugs with fewer secondary effects and higher trypanomicidal activity. The advancement in studies with posaconazole, already commercialized for systemic mycotic infections, and ravuconazole, in the animal experimental phase, is urgent (Villa et al. 2007). However, one of the key issues concerning Chagas disease is still that of diagnosis. Without effective diagnostics, infected individuals cannot be identified and hence treated, and the success of treatment cannot be efficiently assessed. The absence of a true gold standard (i.e., a method to consistently detect the presence of parasites in those T. cruzi-infected individuals) makes it difficult to evaluate the sensitivity of serological tests (Tarleton et al. 2007). The development of highly sensitive and specific diagnostic field and laboratory tools to determine active $T$. cruzi infection is a crucial requirement.

In the last two years, investigators from Latin America recognized the need to standardize and validate PCR-based assays for Chagas disease diagnosis and disease management across laboratories and countries. This necessity was due to the fact that each laboratory applies their own protocols and technologies, making comparison of PCR-based findings among groups unreliable. As an integrated effort of the WHO/TDR and PAHO, a workshop and symposium were held in Buenos Aires (November 2008) supported by TDR, INGEBIConicet UBA and the United Nations University UNUBIOLAC, in which investigators representing different countries established a "Consortium for standardization and validation the clinical use of PCR for T. cruzi DNA detection in Chagas disease". The meeting allowed the definition of the best PCR practices, as well as the applicability of these in a clinical setting and their interpretation (special attention was given to diverse parasite 
lineages); it also allowed establishing the limitations of this technology. All of the obtained information led to the definition of a Standard Operating Procedure (SOP) that could be used by those interested in applying PCR as a diagnostic tool, particularly in some special circumstances (e.g., post transplantation, HIV co-infection, congenital infection) and also for follow-up patient treatment outcome. The special value of this SOP is foreseen in the context of evaluating new drug candidates in clinical studies. This SOP, if validated through use, could also become the standard reference method for evaluating new PCR methodologies.

The implementation of quantitative PCR assays to determine bloodstream parasite load and follow its evolution during treatment could be particularly useful as an indicator of response in prolonged therapeutic regimens (Urbina 2001), as it is mandatory in patient management of certain viral infections (Piatak et al. 1993, Berger \& Preiser 2000). Until now, it has not been well defined if chronic or asymptomatic patients presenting extremely low or even undetectable circulating parasite levels should present a better response to treatment than those with patent parasitaemia. This hypothesis underlines the urgent need to join efforts for standardization of both conventional and real-time PCR protocols, which will probably be the basis for the future establishment of more reliable healing cure criteria for patients submitted to Chagas disease chemotherapy. Moreover, the parasitic load might be a useful epidemiological tool to estimate patients' infectivity concerning the risk of transmission (Schijman et al. 2003).

Studies have been conducted aimed at the development of real-time PCR strategies using both SybrGreen and TaqMan technologies for the diagnosis of $T$. cruzi infection (Cummings \& Tarleton 2003, Virreira et al. 2006, Piron et al. 2007, Duffy et al. 2009), and for molecular typing of the parasite genotypes (Freitas et al. 2005, Burgos et al. 2007, Duffy et al. 2009). Cummings and Tarleton (2003) were pioneers in developing a realtime PCR for accurate and sensitive quantification of tissue parasite burden in mice infected with $T$. cruzi. The method was able to confirm the higher parasite load in mice with acute infections in comparison with chronically infected mice, the detection of tissue-restricted parasite persistence in different parasite: host strain combinations and the observation of increased tissue parasite burden with higher infective inoculation doses. Virreira et al. (2006) compared two PCR methods with primers for both nuclear and kDNA sequences for the diagnosis of congenital infections in amniotic fluids of $T$. cruzi-infected mothers, and also determined the number of parasites in positive samples by real-time PCR (SybrGreen system) targeting the kDNA, following the protocol first described by Cummings and Tarleton (2003), with slight modifications. Piron et al. (2007) developed a real-time PCR based on the use of a TaqMan fluorogenic probe directed to T. cruzi satellite DNA sequences for the detection of parasite DNA in the blood of chagasic patients (adult chronic individuals and one child with an acute congenital infection). A $90 \%$ concordance was achieved using a conventional nested PCR designed for the same parasite target, suggesting that real-time PCR provides an optimal alternative to nested PCR with similar sensitivity and higher throughput and can facilitate in determining ongoing parasitaemia in chagasic patients.

An additional application of real-time PCR was first described by Freitas et al. (2005) and concerns its use for genetically typing major $T$. cruzi lineages directly in chronically infected human tissues (oesophagus, heart and colon) from patients presenting gastrointestinal or cardiac forms of Chagas disease. The high sensitivity of PCR-based typing provides direct assessment of parasite genetic diversity in clinical specimens without the need of culture isolation. Following PCR amplification with the SybrGreen system targeting the parasite ribosomal DNA, the products were precisely identified using thermal denaturation curves in real-time. Burgos et al. (2007) used a similar approach with primers directed to nuclear genomic markers to identify bloodstream $T$. cruzi lineages in the blood of congenitally infected children and their mothers from endemic localities of Argentina and Bolivia. The results indicated no association between a particular T. cruzi genotype and vertical transmission of Chagas disease in these countries.

More recently, Duffy et al. (2009) developed an accurate real-time PCR strategy using SybrGreen targeted to conserved motifs within the T. cruzi repetitive satellite sequence for monitoring Chagas disease reactivation in heart-transplanted patients who received immunosuppressive therapy, and also for etiological treatment outcome in paediatric patients. The approach was able to identify parasites according to the number of satellite repeats detected per genome for different $T$. cruzi lineages. In this work, the addition of a standardized amount of plasmid containing a heterologous sequence allows normalization of the DNA extraction yields and detection of false-negatives due to inhibition under any clinical situation.

In general, the true potential of real-time PCR will be recognized in situations for which PCR-based techniques have been promoted, such as congenital infections (Schijman et al. 2003, Virreira et al. 2003, Mora et al. 2005), monitoring parasitaemia during and after treatment (Russomando et al. 1998, Britto et al. 2001, Schijman et al. 2003, Apt et al. 2005, Sánchez et al. 2005), early detection of relapses after heart transplantation (Maldonado et al. 2004) and other immunosuppressive circumstances. To deal with more precise results and make them comparable between laboratories, the main constraint until now has been the lack of a universal reagent presenting accurately quantified $T$. cruzi DNA samples to be used as standards in all quantification assays (Piron et al. 2007). International standards for various infectious agents (human immunodeficiency virus, hepatitis $\mathrm{C}$ virus, etc.) are commercially available for molecular biology assays in order to standardize and compare methods and laboratory performances. In this sense, agencies providing such materials should be strongly encouraged to make properly characterized $T$. cruzi reagents available for this purpose. 


\section{REFERENCES}

Andrade AL, Martelli CM, Oliveira RM, Silva SA, Aires AI, Soussumi LM, Covas DT, Silva LS, Andrade JG, Travassos LR, Almeida IC 2004. Short report: benznidazole efficacy among Trypanosoma cruzi-infected adolescents after a six-year follow-up. Am J Trop Med Hyg 71: 594-597.

Andrade AL, Zicker F, de Oliveira RM, Almeida Silva S, Luquetti A, Travassos LR, Almeida IC, De Andrade SS, de Andrade JG, Martelli CM 1996. Randomized trial of efficacy of benznidazole in treatment of early Trypanosoma cruzi infection. Lancet 348: 1407-1413.

Andrade SG, Figueira RM, Carvalho ML, Gorini DF 1975. Reaction of the Trypanosoma cruzi strains to the experimental therapeutical response to Bay 2502 (results of long term treatment). Rev Inst Med Trop Sao Paulo 17: 380-399.

Andrade SG, Freitas LAR, Peyrol S, Pimentel AR, Sadigursky M 1988. Trypanosoma cruzi antigens detected by immunoelectron microscopy in the spleen of mice serologically positive but parasitologically cured by chemotherapy (preliminary report). Rev Soc Bras Med Trop 21: 41-42.

Andrade SG, Freitas LAR, Peyrol S, Pimentel AR, Sadigursky M 1991. Experimental chemotherapy of Trypanosoma cruzi reveals infection persistence of parasite antigens and positive sorology in parasitologically cured mice. Bull World Health Organ 69: 191-199.

Andrade SG, Magalhães JB 1996. Biodemes and zymodemes of Trypanosoma cruzi strains: correlations with clinical data and experimental pathology. Rev Soc Bras Med Trop 30: 27-35.

Andrade SG, Magalhães JB, Pontes AL 1985. Evaluation of chemotherapy with benznidazole and nifurtimox in mice infected with Trypanosoma cruzi strains of different types. Bull World Health Organ 63: 721-726.

Andrade SG, Rassi A, Magalhaes JB, Ferriolli Filho F, Luquetti AO 1992. Specific chemotherapy of Chagas disease: a comparison between the response in patients and experimental animals inoculated with the same strains. Trans R Soc Trop Med Hyg 86: 624-626.

Andrade ZA, Andrade SG, Sadigursky M 1987. Enhancement of chronic Trypanosoma cruzi myocarditis in dogs treated with low doses of cyclophosphamide. Am J Pathol 127: 467-473.

Apt W, Aguilera X, Arribada A, Perez C, Miranda C, Sanchez G, Zulantay I, Cortes P, Rodriguez J, Juri D 1998. Treatment of chronic Chagas disease with itraconazole and allopurinol. Am J Trop Med Hyg 59: 133-138.

Apt W, Arribada A, Zulantay I, Solari A, Sánchez G, Mundana K, Coronado X, Rodríguez G, Gil LC, Osuna A 2005. Itraconazole or allopurinol in the treatment of chronic American trypanosomiasis: the results of clinical and parasitological examinations 11 years post-treatment. Ann Trop Med Parasitol 99: 733-741.

Avila HA, Borges-Pereira J, Thiemann O, de Paiva E, Degrave W, Morel CM, Simpson L 1993. Detection of Trypanosoma cruzi in blood specimens of chronic chagasic patients by polymerase chain reaction amplification of kinetoplast minicircle DNA: comparison with serology and xenodiagnosis. J Clin Microbiol 31: 2421-2426.

Avila HA, Sigman DS, Cohen LM, Millikan RC, Simpson L 1991. Polymerase chain reaction amplification of Trypanosoma cruzi kinetoplast minicircle DNA isolated from whole blood lysates: diagnosis of chronic Chagas disease. Mol Biochem Parasitol 48: 211-222.

Bellotti G, Bocchi EA, de Moraes AV, Higuchi ML, Barbero-Marcial M, Sosa E, Esteves-Filho A, Kalil R, Weiss R, Jatene A, Pileggi F 1996. In vivo detection of Trypanosoma cruzi antigens in hearts of patients with chronic Chagas' heart disease. Am Heart J 131: 301-317.
Berger A, Preiser W 2000. Viral genome quantification as a tool for improving patient management: the example of HIV, HBV, HCV and CMV. J Antimicrob Chemother 49: 713-721.

Bittencourt AL 1992. Possible risk factors for vertical transmission of Chagas' disease. Rev Inst Med Trop São Paulo 34: 403-408.

Blanco SB, Segura EL, Cura EN, Chuit R, Tulián L, Flores I, Garbarino G, Villalonga JF, Gürtler RE 2000. Congenital transmission of Trypanosoma cruzi: an operational outline for detecting and treating infected infants in North-Western Argentina. Trop Med Int Health 5: 293-301.

Blanco SB, Segura EL, Gürtler RE 1999. El control de la transmisión congénita de T. cruzi en la Argentina. Medicina (B Aires) 59 (Suppl. 2): 138-142.

Bocchi EA, Fiorelli A 2001. First Guideline Group for Heart Transplantation of the Brazilian Society of Cardiology. The Brazilian experience with heart transplantation: a multicenter report. J Heart Lung Transplant 20: 637-645.

Bosseno MF, Yacsik N, Vargas F, Brenière SF 2000. Selection of Trypanosoma cruzi clonal genotypes (clones 20 and 39) isolated from Bolivian triatomines following subculture in liquid medium. Mem Inst Oswaldo Cruz 95: 601-607.

Brandariz S, Schijman A, Vigliano C, Arteman P, Viotti R, Beldjord C, Levin MJ 1995. Detection of parasite DNA in Chagas' heart disease [Letter]. Lancet 346: 1370-1371.

Brener Z 1962. Therapeutic activity and criterion of cure on mice experimentally infected with Trypanosoma cruzi. Rev Inst Med Trop São Paulo 4: 389-396.

Brener Z, Andrade Z, M Barral-Netto 2000. Trypanosoma cruzi e doença de Chagas, $2^{\mathrm{a}}$ ed., Guanabara Koogan, Rio de Janeiro, 431 pp.

Brenière SF, Bosseno MF, Telleria J, Bastrenta B, Yacsik N, Noireau F, Alcazar JL, Barnabé C, Wincker P, Tibayrenc M 1998. Different behavior of two Trypanosoma cruzi major clones: transmission and circulation in young Bolivian patients. Exp Parasitol 89: 285-295.

Britto C, Cardoso MA, Vanni CMM, Haslocher-Moreno A, Xavier SS, Wincker P 1995. Polymerase chain reaction detection of Trypanosoma cruzi in human blood samples as a tool for diagnosis and treatment evaluation. Parasitology 110: 241-247.

Britto C, Cardoso MA, Wincker P, Morel CM 1993. A simple protocol for the physical cleavage of Trypanosoma cruzi kinetoplast DNA present in blood samples and its use in polymerase chain reaction (PCR)-based diagnosis of chronic Chagas disease. Mem Inst Oswaldo Cruz 88: 171-172.

Britto C, Silveira C, Cardoso MA, Marques P, Luquetti A, Macedo V, Fernandes O 2001. Parasite persistence in treated chagasic patients revealed by xenodiagnosis and polymerase chain reaction. Mem Inst Oswaldo Cruz 96: 823-826.

Burgos JM, Altcheh J, Bisio M, Duffy T, Valadares HM, Seidenstein ME, Piccinali R, Freitas JM, Levin MJ, Macchi L, Macedo AM, Freilij H, Schijman AG 2007. Direct molecular profiling of minicircle signatures and lineages of Trypanosoma cruzi bloodstream populations causing congenital Chagas disease. Int $J$ Parasitol 37: 1319-1327.

Cançado JR 1963. Aspectos clínicos na padronização dos métodos de avaliação terapêutica na doença de Chagas. Rev Goiana Med 9 (Suppl.): 212-232.

Cançado JR 1985. Tratamento específico. In JR Cançado, M Chuster, Cardiopatia chagásica, Imprensa Oficial de Minas Gerais, Minas Gerais, p. 327-355. 
Cançado JR 1997. Terapêutica específica. In JCP Dias, JR Coura, Clínica e terapêutica da doença de Chagas. Uma abordagem prática para o clínico geral, Fiocruz, Rio de Janeiro, p. 323-351.

Cançado JR 1999. Criteria of Chagas disease cure. Mem Inst Oswaldo Cruz 94 (Suppl. I): 331-335.

Cançado JR 2002. Long term evaluation of etiological treatment of Chagas disease with benznidazole. Rev Inst Med Trop Sao Paulo 44: 29-37.

Castro AM, Luquetti AO, Rassi A, Rassi GG, Chiari E, Galvão LMC 2002. Blood culture and polymerase chain reaction for the diagnosis of the chronic phase of human infection with Trypanosoma cruzi. Parasitol Res 88: 894-900.

Chiari E, Dias JCP, Lana M, Chiari CA 1989. Hemocultures for the parasitological diagnosis of human chronic Chagas disease. Rev Soc Bras Med Trop 22: 19-23.

Coronado X, Zulantay I, Rozas M, Apt W, Sánchez G, Rodríguez J, Ortiz S, Solari A 2006. Dissimilar distribution of Trypanosoma cruzi clones in humans after chemotherapy with allopurinol and itraconazole. J Antimicrob Chemother 58: 216-219.

Coura JR 2007. Chagas disease: what is known and what is needed - A background article. Mem Inst Oswaldo Cruz 102 (Suppl. I): $113-122$.

Coura JR, de Castro SL 2002. A critical review on Chagas disease chemotherapy. Mem Inst Oswaldo Cruz 97: 3-24.

Coura JR, Junqueira AC, Fernandes O, Valente SA, Miles MA 2002. Emerging Chagas disease in Amazonian Brazil. Trends Parasitol 18: $171-176$.

Cummings KL, Tarleton RL 2003. Rapid quantitation of Trypanosoma cruzi in host tissue by real-time PCR. Mol Biochem Parasitol 129: $53-59$

Cunha-Neto E, Bilate AM, Hyland KV, Fonseca SG, Kalil J, Engman DM 2006. Induction of cardiac autoimmunity in Chagas heart disease: a case for molecular mimicry. Autoimmunity 39: 41-54.

Cunha-Neto E, Coelho V, Guilherme L, Fiorelli A, Stolf N, Kalil J 1996. Autoimmunity in Chagas' disease. Identification of cardiac myosin-B13 Trypanosoma cruzi protein crossreactive T cell clones in heart lesions of a chronic Chagas' cardiomyopathy patient. J Clin Invest 98: 1709-1712.

da Silveira Pinto A, de Lana M, Bastrenta B, Barnabé C, Quesney V, Noel S, Tibayrenc M 1998. Compared vectorial transmissibility of pure and mixed clonal genotypes of Trypanosoma cruzi in Triatoma infestans. Parasitol Res 84: 348-353.

da Silveira Pinto A, de Lana M, Britto C, Bastrenta B, Tibayrenc M 2000. Experimental Trypanosoma cruzi biclonal infection in Triatoma infestans: detection of distinct clonal genotypes using kinetoplast DNA probes. Int J Parasitol 30: 843-848.

Deane MP, Mangia RH, Pereira NM, Momen H, Gonçalves AM, Morel CM 1984. Trypanosoma cruzi: strain selection by different schedules of mouse passages of an initially mixed infection. Mem Inst Oswaldo Cruz 79: 495-497.

de Castro AM, Luquetti AO, Rassi A, Chiari E, Galvao LM 2006. Detection of parasitemia profiles by blood culture after treatment of chronic Trypanosoma cruzi infection. Parasitol Res 99: 379-383.

Duffy T, Bisio M, Altcheh J, Burgos JM, Diez M, Levin MJ, Favaloro RR, Freilij H, Schijman AG 2009. Accurate real-time PCR strategy for monitoring bloodstream parasitic loads in Chagas disease patients. PLoS Negl Trop Dis 3: e419.

Fabbro De Suasnábar D, Arias E, Streiger M, Piacenza M, Ingaramo M, Del Barco M, Amicone N 2000. Evolutive behavior towards cardiomyopathy of treated (nifurtimox or benznidazole) and un- treated chronic chagasic patients. Rev Inst Med Trop Sao Paulo 42: 99-109.

Fernandes O, Santos SS, Cupolillo E, Mendonça B, Derre R, Junqueira AC, Santos LC, Sturm NR, Naiff RD, Barret TV, Campbell DA, Coura JR 2001. A mini-exon multiplex polymerase chain reaction to distinguish the major groups of Trypanosoma cruzi and T. rangeli in the Brazilian Amazon. Trans $R$ Soc Trop Med Hyg 95: 97-99.

Filardi LS, Brener Z 1987. Susceptibility and natural-resistance of Trypanosoma cruzi strains to drugs used clinically in Chagas disease. Trans R Soc Trop Med Hyg 5: 755-759.

Fragata Filho AA, Luquetti AO, Prata A, Rassi A, Gontijo ED, Ferreira HO, Cançado JR, Andrade SG, Macedo V, Amato Neto A, Oliveira Jr W, Brener Z 1997. Ethiological treatment for Chagas' disease. Parasitol Today 13: 127-128.

Freilij H, Altcheh J 1995. Congenital Chagas' disease. Diagnostic and clinical aspects. Clin Infect Dis 21: 551-555.

Freilij H, Muller L, Gonzalez-Cappa EM 1983. Direct micromethod for diagnosis of acute and congenital Chagas disease. J Clin Microbiol 18: 327-330.

Freitas JM, Lages-Silva E, Crema E, Pena SD, Macedo AM 2005. Real time PCR strategy for the identification of major lineages of Trypanosoma cruzi directly in chronically infected human tissues. Int J Parasitol 35: 411-417.

Galleano RH, Marr JJ, Sosa RR 1990. Therapeutic efficacy of allopurinol in patients with chronic Chagas disease. Am J Trop Med Hyg 43: 159-166.

Galvão LMC, Chiari E, Macedo AM, Luquetti AO, Silva SA, Andrade AL 2003. PCR assay for monitoring Trypanosoma cruzi parasitemia in childhood after specific chemotherapy. J Clin Microbiol 41: 5066-5070.

Galvão LMC, Nines RMB, Cançado JR, Brener Z, Krettli AU 1993. Lytic antibody titre as a means of assessing cure after treatment of Chagas disease: a 10 years follow-up study. Trans $R$ Soc Trop Med Hyg 87: 220-223.

Girones N, Cuervo H, Fresno M 2005. Trypanosoma cruzi-induced molecular mimicry and Chagas disease. Curr Trop Microbiol Immunol 296: 89-123.

Gomes ML, Galvão LM, Macedo AM, Pena SD, Chiari E 1999. Chagas disease diagnosis: comparative analysis of parasitologic, molecular and serologic methods. Am J Trop Med Hyg 60: 205-210.

Gomes ML, Macedo AM, Vago AR, Pena SD, Galvão LM, Chiari E 1998. Trypanosoma cruzi: optimization of polymerase chain reaction for detection in human blood. Exp Parasitol 88: 28-33.

Guedes PMM, Fietto JLR, Lana M, Bahia MT 2006. Advances in Chagas disease chemotherapy. Anti-Infect Agents Med Chem 5: $175-186$.

Guzmán-Brancho C 2001. Epidemiology of Chagas disease in Mexico: an update. Trends Parasitol 17: 372-377.

Higuchi ML, Brito T, Reis M, Bellotti G, Pereira-Barreto AC, Pileggi F 1993. Correlation between Trypanosoma cruzi parasitism and myocardial inflammation in human chronic chagasic myocardits. Light microscopy and immunohistochemical findings. Cardiovasc Pathol 2: 101-106.

Iwai LK, Juliano MA, Juliano L, Kalil J, Cunha-Neto E 2005. T-cell molecular mimicry in Chagas disease: identification and partial structural analysis of multiple cross-reactive epitopes between Trypanosoma cruzi B13 and cardiac myosin heavy chain. J Autoimmun 24: 111-117. 
Jones EM, Colley DG, Tostes S, Lopes ER, Venencak-Jones C, Mc Curley TL 1993. Amplification of Trypanosoma cruzi DNA sequence from inflammatory lesions in human chagasic cardiomyopathy. Am J Trop Med Hyg 48: 348-357.

Junqueira ACV, Chiari E, Wincker P 1996. Comparison of the polymerase chain reaction with two classical parasitological methods for the diagnosis of Chagas disease in endemic region of NorthEastern Brazil. Trans R Soc Trop Med Hyg 90: 129-132.

Kalil J, Cunha-Neto E 1996. Autoimmunity in Chagas disease cardiomyopathy: fulfilling the criteria at last? Parasitol Today 12: 396-399.

Kierszenbaum F 1999. Chagas' disease and the autoimmunity hypothesis. Clin Microbiol Rev 12: 210-223.

Krettli AU, Brener Z 1982. Resistance against Trypanosoma cruzi associate to anti-living trypomastigote antibodies. J Immunol 128: 2009-2012.

Krettli AU, Cançado JR, Brener Z 1982. Effect of specific chemotherapy on the levels of lytic antibodies in Chagas' disease. Trans R Soc Trop Med Hyg 76: 334-340.

Krettli AU, Cançado R, Brener Z 1984. Criterion of cure of human Chagas disease after specific chemotherapy: recent advances. Mem Inst Oswaldo Cruz 79: 157-164.

Lages-Silva E, Ramirez LE, Silva-Vergara ML, Chiari E 2002. Chagasic meningoencephalitis in a patient with acquired immunodeficiency syndrome: diagnosis, follow-up and genetic characterization of Trypanosoma cruzi. Clin Infect Dis 34: 118-123.

Lane JE, Olivares-Villagomez D, Vnencak-Jones CL, McCurley TL, Carter CE 1997. Detection of Trypanosoma cruzi with the polymerase chain reaction and in situ hybridization in infected murine cardiac tissue. Am J Trop Med Hyg 56: 588-595.

Lauria-Pires L, Braga MS, Vexenat AC, Nitz N, Simões-Barbosa A, Tinoco DL, Teixeira AR 2000. Progressive chronic Chagas heart disease ten years after treatment with anti-Trypanosoma cruzi nitroderivatives. Am J Trop Med Hyg 63: 111-118.

Lauria-Pires L, Castro CN, Emanuel A, Prata A 1988. Ineficácia do allopurinol em pacientes na fase aguda da doença de Chagas. Rev Soc Bras Med Trop 21: 79.

Levin MJ 1996. In chronic Chagas heart disease, don't forget the parasite. Parasitol Today 12: 415-416.

Luquetti A 1997. The National Health Foundation of Brazil, etiological treatment for Chagas disease. Parasitol Today 13: 127-128.

Machado CR, Camargos ER, Guerra LB, Moreira MC 2000. Cardiac autonomic denervation in congestive heart failure: comparison of Chagas' heart disease with other dilated cardiomyopathy. Hum Pathol 31: 3-10.

Maldonado C, Albano S, Vettorazzi L, Salomone O, Zlocowski JC, Abiega C, Amuchastegui M, Cordoba R, Alvarellos T 2004. Using polymerase chain reaction in early diagnosis of reactivated Trypanosoma cruzi infection after heart transplantation. J Heart Lung Transplant 23: 1345-1348.

Manzullo EC, Chuit R 1999. Risk of death due to chronic chagasic cardiopathy. Mem Inst Oswaldo Cruz 94 (Suppl. I): 317-320.

Marin-Neto JA, Cunha-Neto E, Maciel BC, Simões MV 2007. Pathogenesis of chronic Chagas heart disease. Circulation 115: 1109-1123.

Marin-Neto JA, Rassi A Jr, Morillo CA, Avezum A, Connolly SJ, Sosa-Estani S, Rosas F, Yusuf S, BENEFIT Investigators 2008. Rationale and design of a randomized placebo-controlled trial assessing the effects of etiologic treatment in Chagas' cardiomyopathy: the BENznidazole Evaluation for Interrupting Trypanosomiasis (BENEFIT). Am Heart J 156: 37-43.
Martins HR, Moreira Silva R, Valadares HM, Toledo MJ, Veloso VM, Vitelli-Avelar DM, Carneiro CM, Machado-Coelho GL, Bahia MT, Martins-Filho OA, Macedo AM, Lana M 2007. Impact of dual infections on chemotherapeutic efficacy in BALB/c mice infected with major genotypes of Trypanosoma cruzi. Antimicrob Agents Chemother 51: 3282-3289.

Martins HR, Toledo MJ, Veloso VM, Carneiro CM, Machado-Coelho GL, Tafuri WL, Bahia MT, Valadares HM, Macedo AM, Lana M 2006. Trypanosoma cruzi: impact of dual-clone infections on parasite biological properties in BALB/c mice. Exp Parasitol 112: 237-246.

Medrano NM, Luz MRMP, Cabello P, Tapia GT, Van Leuven F, Araújo-Jorge TC 1996. Acute Chagas disease: plasma levels of alpha-2macroglobulin and C-reactive protein in children under 13 years in a high endemic area of Bolivia. J Trop Pediatr 42: 68-74.

Mora MC, Sánchez Negrette O, Marco D, Barrio A, Ciaccio M, Segura MA, Basombrio MA 2005. Early diagnosis of congenital Trypanosoma cruzi infection using PCR, hemoculture and capillary concentration as compared with delayed serology. J Parasitol 91: 1468-1473.

Moser DR, Kirchoff LV, Donelson JE 1989. Detection of Trypanosoma cruzi by DNA amplification using the polymerase chain reaction. J Clin Microbiol 27: 1477-1482.

Moya PR, Moretti E, Paolasso R, Blanco S, Sanmartino C, Soich de Cura A 1989. Enfermedad de Chagas neonatal. Diagnóstico de laboratorio en el primer año de vida. Medicina (B Aires) 49: 595-599.

MS - Ministério da Saúde 2005. Consenso Brasileiro em Doença de Chagas. Rev Soc Bras Med Trop 38 (Suppl. III): 1-29.

Murta SM, Nogueira FB, Dos Santos PF, Campos FM, Volpe C, Liarte DB, Nirdé P, Probst CM, Krieger MA, Goldenberg S, Romanha AJ 2008. Differential gene expression in Trypanosoma cruzi populations susceptible and resistant to benznidazole. Acta Trop 107: 59-65.

Olivares-Villagómez D, McCurley TL, Vnencak-Jones CL, CorreaOliveira R, Colley DG, Carter CE 1998. Polymerase chain reaction amplification of three different Trypanosoma cruzi DNA sequences from human chagasic cardiac tissue. Am J Trop Med Hyg 59: 563-570.

OPAS/OMS 1998. Tratamiento Etiológico de la Enfermedad de Chagas. Conclusiones de una consulta técnica. Rev Patol Trop 28: 247-279, 1999.

Piatak M Jr, Luk KC, Williams B, Lifson JD 1993. Quantitative competitive polymerase chain reaction for accurate quantitation of HIV DNA and RNA species. Biotechniques 14: 70-81.

Piron M, Fisa R, Casamitjana N, López-Chejade P, Puig L, Vergés M, Gascón J, Gómez i Prat J, Portús M, Sauleda S 2007. Development of a real-time PCR assay for Trypanosoma cruzi detection in blood samples. Acta Trop 103: 195-200.

Pontes-de-Carvalho L, Santana CC, Soares MB, Oliveira GG, CunhaNeto E, Ribeiro-dos-Santos R 2002. Experimental chronic Chagas' disease myocarditis is an autoimmune disease preventable by induction of immunological tolerance to myocardial antigens. J Autoimmun 18: 131-138.

Rassi A, Luquetti AO 1992. Therapy of Chagas disease. In S Wendel, Z Brener, E Camargo, A Rassi, Chagas disease (American trypanosomiasis): its impact on transfusion and clinical medicine, ISBT, São Paulo, p. 237-247.

Rassi A, Luquetti AO 2003. Specific treatment for Trypanosoma cruzi infection (Chagas disease). In KM Tyler, Miles MA, American trypanosomiasis, Kluwer Academic Publishers, Boston, p. 117-125. 
Rassi Jr A, Rassi A, Little WC 2000. Chagas' heart disease. Clin Cardiol 23: 883-889.

Rassi Jr A, Rassi SG, Rassi A 2001. Sudden death in Chagas' disease. Arq Bras Cardiol 76: 75-96.

Revollo S, Oury B, Laurent JP, Barnabé C, Quesney V, Carriere V, Noel S, Tibayrenc M 1998. Trypanosoma cruzi: impact of clonal evolution of the parasite on its biological and medical properties. Exp Parasitol 89: 30-39.

Russomando G, de Tomassone MM, de Guillen I, Acosta N, Vera N, Almiron M, Candia N, Calcena MF, Figueredo A 1998. Treatment of congenital Chagas' disease diagnosed and followed up by the polymerase chain reaction. Am J Trop Med Hyg 59: 487-491.

Sánchez G, Coronado X, Zulantay I, Apt W, Gajardo M, Solari S, Venegas J 2005. Monitoring the efficacy of specific treatment in chronic Chagas disease by polymerase chain reaction and flow cytometry analysis. Parasite 12: 353-357.

Schijman AG, Altcheh J, Burgos JM, Biancardi M, Bisio M, Levin MJ, Freilij H 2003. Aetiological treatment of congenital Chagas' disease diagnosed and monitored by the polymerase chain reaction. J Antimicrob Chemother 52: 441-449.

Schijman AG, Vigliano C, Burgos J, Favaloro R, Perrone S, Laguens R, Levin MJ 2000. Early diagnosis of recurrence of Trypanosoma cruzi infection by polymerase chain reaction after heart transplantation of a chronic Chagas' heart disease patient. J Heart Lung Transplant 19: 1114-1117.

Schofield CJ, Dias JCP 1999. The Southern Cone Initiative against Chagas disease. Adv Parasitol 42: 1-27.

Silva JS, Rossi MA 1990. Intensification of acute Trypanosoma cruzi myocarditis in BALB/c mice pretreated with low doses of cyclophosphamide or gamma irradiation. J Exp Pathol 71: 33-39.

Solari A, Ortíz S, Soto A, Arancibia C, Campillay R, Contreras M, Salinas P, Rojas A, Schenone H 2001. Treatment of Trypanosoma cruzi-infected children with nifurtimox: a 3 year follow-up by PCR. J Antimicrob Chemother 48: 515-519.

Sosa-Estani S, Segura EL 1999. Treatment of Trypanosoma cruzi infection in the undetermined phase. Experience and current guidelines of treatment in Argentina. Mem Inst Oswaldo Cruz 94 (Suppl. I): 363-365.

Sosa-Estani S, Segura EL 2006. Etiological treatment in patients infected by Trypanosoma cruzi: experiences in Argentina. Curr Opin Infect Dis 19: 583-587.

Sosa-Estani S, Segura EL, Ruiz AM, Velazquez E, Porcel BM, Yampotis C 1998. Efficacy of chemotherapy with benznidazole in children in the indeterminate phase of Chagas disease. Am J Trop Med Hyg 59: 526-529.

Sturm NR, Degrave W, Morel CM, Simpson L 1989. Sensitive detection by amplification of kinetoplast minicircle DNA sequences: use in diagnosis of Chagas disease. Mol Biochem Parasitol 33: 205-214.

Tarleton RL 2001. Parasite persistence in the aetiology of Chagas disease. Int J Parasitol 31: 550-554.

Tarleton RL, Reithinger R, Urbina JA, Kitron U, Gürtler RE 2007. The challenges of Chagas disease - grim outlook or glimmer of hope? PLoS Med 4: 1852-1857.

Tarleton RL, Zhang L 1999. Chagas' disease etiology: autoimmunity or parasite persistence? Parasitol Today 15: 94-99.

Tibayrenc M, Ward P, Moya A, Ayala FJ 1986. Natural populations of Trypanosoma cruzi, the agent of Chagas disease, have a complex multiclonal structure. Proc Natl Acad Sci USA 83: 115-119.

Toledo MJ, Bahia MT, Carneiro CM, Martins-Filho OA, Tibayrenc M, Barnabé C, Tafuri WL, de Lana M 2003. Chemotherapy with benznidazole and itraconazole for mice infected with different Trypanosoma cruzi clonal genotypes. Antimicrob Agents Chemother 47: 223-230.

Toledo MJ, Bahia MT, Veloso VM, Carneiro CM, Machado-Coelho GL, Alves CF, Martins HR, Cruz RE, Tafuri WL, Lana M 2004. Effects of specific treatment on parasitological and histopathological parameters in mice infected with different Trypanosoma cruzi clonal genotypes. J Antimicrob Chemother 53: 1045-1053.

Urbina JA 2001. Specific treatment of Chagas disease: current status and new developments. Curr Opin in Infect Dis 14: 733-741.

Urbina JA, Docampo R 2003. Specific chemotherapy of Chagas disease: controversies and advances. Trends Parasitol 19: 495-501.

Vago AR, Macedo AM, Adad SJ, Reis DD, Corrêa-Oliveira R 1996. PCR detection of Trypanosoma cruzi DNA in oesophageal tissues of patients with chronic digestive Chagas' disease. Lancet 348: 891-892.

Villa L, Morote S, Bernal O, Bulla D, Albajar-Vinas P 2007. Access to diagnosis and treatment of Chagas disease/infection in endemic and non-endemic countries in the XXI century. Mem Inst Oswaldo Cruz 102 (Suppl. I): 87-93.

Viotti R, Vigliano C, Armenti H, Segura E 1994. Treatment of chronic Chagas disease with benznidazole: clinical and serologic evolution of patients with long-term follow-up. Am Heart J 127: 151-162.

Viotti R, Vigliano C, Lococo B, Bertocchi G, Petti M, Alvarez MG, Postan M, Armenti A 2006. Long-term cardiac outcomes of treating chronic Chagas disease with benznidazole versus no treatment: a nonrandomized trial. Ann Intern Med 144: 724-734.

Virreira M, Martínez S, Alonso-Vega C, Torrico F, Solano M, Torrico MC, Parrado R, Truyens C, Carlier Y, Svoboda M 2006. Amniotic fluid is not useful for diagnosis of congenital Trypanosoma cruzi infection. Am J Trop Med Hyg 75: 1082-1084.

Virreira M, Torrico F, Truyens C, Alonso-Vega C, Solano M, Carlier Y, Svoboda M 2003. Comparison of polymerase chain reaction methods for reliable and easy detection of congenital Trypanosoma cruzi infection. Am J Trop Med Hyg 68: 574-582.

Virreira M, Torrico F, Truyens C, Alonso-Vega C, Solano M, Carlier Y, Svoboda M 2005. Comparison of PCR methods for the diagnosis of congenital Trypanosoma cruzi infection. Rev Soc Bras Med Trop 38 (Suppl. II): 65-67.

Wendel S, Dias JCP 1992. Transfusion transmitted Chagas disease. In $\mathrm{S}$ Wendel, Z Brener, E Camargo, A Rassi, Chagas disease (American trypanosomiasis): its impact on transfusion and clinical medicine, ISBT, São Paulo, p. 103-134.

WHO - World Health Organization 1991. Control of Chagas disease. WHO Techn Rep Sers 811: 2-11.

WHO - World Health Organization 2005. Chagas disease. Seventeenth Programme Report UNDP/TDR, Geneva.

Winker P, Bosseno MF, Britto C, Yaksic N, Cardoso MA, Morel CM, Brenière SF 1994a. High correlation between Chagas' disease serology and PCR-based detection of Trypanosoma cruzi kinetoplast DNA in Bolivian children living in an endemic area. FEMS Microbiol Lett 124: 419-423.

Winker P, Britto C, Borges Pereira J, Cardoso MA, Oelemann W, Morel CM 1994b. Use of simplified polymerase chain reaction procedure to detect Trypanosoma cruzi in blood samples from chronic chagasic patients in a rural endemic area. Am J Trop Med Hyg 51: 771-777. 
Winker P, Telleria J, Bosseno MF, Cardoso MA, Marques P, Yaksic N, Aznar C, Liegeard P, Hontebeyrie M, Noireau F, Morel CM, Brenière SF 1997. PCR-based diagnosis for Chagas' disease in Bolivian children living in an active transmission area: comparison with conventional serology and parasitological diagnosis. Parasitology 114: 367-373.

Zingales B, Souto RP, Mangia RH, Lisboa CV, Campbell DA, Coura JR, Jansen A, Fernandes O 1998. Molecular epide- miology of American trypanosomiasis in Brazil based on dimorphisms of rRNA and mini-exon gene sequences. Int $J$ Parasitol 28: 105-112.

Zulantay I, Honores P, Solari A, Apt W, Ortiz S, Osuna A, Rojas A, López B, Sánchez G 2004. Use of polymerase chain reaction (PCR) and hybridization assays to detect Trypanosoma cruzi in chronic chagasic patients treated with itraconazole or allopurinol. Diag Microbiol Infect Dis 48: 253-257. 